\title{
In memoriam: Nelly Sturm-Klein (1924-2017) en haar verzet binnen de Duitse communistische groep Travail allemand
}

'Ben je het niet beu om de tegels van de rijken te schrobben? Wil je niet liever samen met ons in de weerstand werken?'

"Tu n'en as pas assez de frotter le carrelage des riches? [...] Tu ne préférerais pas travailler avec nous dans la résistance? "In memoriam Nelly Sturm, née Klein (1924-2017) et ses activités de résistante au sein du groupe communiste Travail allemand pendant l'occupation allemande de la Belgique

\section{Tanja von Fransecky}

Traducteur : Rita Roggen

\section{(2) OpenEdition}

\section{Journals}

Édition électronique

URL : https://journals.openedition.org/temoigner/7407

DOI : $10.4000 /$ temoigner.7407

ISSN : 2506-6390

Cet article est une traduction de :

"Tu n'en as pas assez de frotter le carrelage des riches ? [...] Tu ne préférerais pas travailler avec nous dans la résistance ?" - URL : https://journals.openedition.org/temoigner/7352 [fr]

Éditeur :

Éditions du Centre d'études et de documentation Mémoire d'Auschwitz, Éditions Kimé

\section{Édition imprimée}

Date de publication : 2 avril 2018

Pagination : 112-117

ISBN : 978-2-930953-06-9

ISSN : 2031-4183

Référence électronique

Tanja von Fransecky, «In memoriam: Nelly Sturm-Klein (1924-2017) en haar verzet binnen de Duitse communistische groep Travail allemand », Témoigner. Entre histoire et mémoire [Online], 126 | 2018, Online op 24 janvier 2022, geraadpleegd op 04 février 2022. URL: http://journals.openedition.org/ temoigner/7407 ; DOl: https://doi.org/10.4000/temoigner.7407 


\section{In memoriam: \\ Nelly Sturm-Klein (1924-2017) \\ en haar verzet binnen de \\ Duitse communistische groep Travail allemand}

'Ben je het niet beu om de tegels van de rijken te schrobben? Wil je niet liever samen met ons in de weerstand werken?'

$\rightarrow$ Tanja von Fransecky

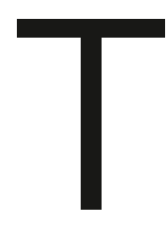

en de Duitse Wehrmacht in maart 1938 Oostenrijk binnenviel en het land annexeerde, gingen de nieuwe machthebbers meteen over tot de vervolging van de politieke tegenstanders en de Joodse bevolking. Vooral in Wenen, waar de meeste Oostenrijkse Joden woonden, organiseerden deSA, de SS, de HJ en delen van de bevolking een pogrom tegen de zowat 200000 Joden die daar leefden. De terreur duurde maanden en zorgde ervoor dat velen op de vlucht sloegen.

Ook de dertienjarige Nelly Klein vluchtte aan het eind van de zomer van 1939 met haar ouders Elisabeth en Koloman Klein van Wenen naar België. Geen jaar later, op 10 mei 1940, werden ze daar ing Kald door de Wehrmacht. Meteen nadat die op 10 mis de grens was on Oostenrijkse migranten gevangen, onder hen veel Joden en politieke tegenstander van het nationaalsocialisme. Ze werden verdacht als 'vijfde colonne', spionnen van Hitler. Ook voormalige Oostenrijkers werden gevangengenomen, omdat ze sinds de annexatie van Oostenrijk in 1938 Duitse staatsburgers waren.

Op grond van een verdrag tussen de Franse en Belgische overheid, dat inging tegen het internationaal recht, werden de aangehouden mannen naar bestaande interneringskampen in Zuid-Frankrijk gedeporteerd. De kampen werden oorspronkelijk door de Franse regering ingericht voor de opsluiting van leden van de Internationale Brigades die terugkeerden uit de Spaanse Burgeroorlog Het lot van de deportatie nat Frankrijk trof op 14 mei 1940 ook Koloman Klein. Nadat Nelly (a) Nelly en Elisabeth Klein hem

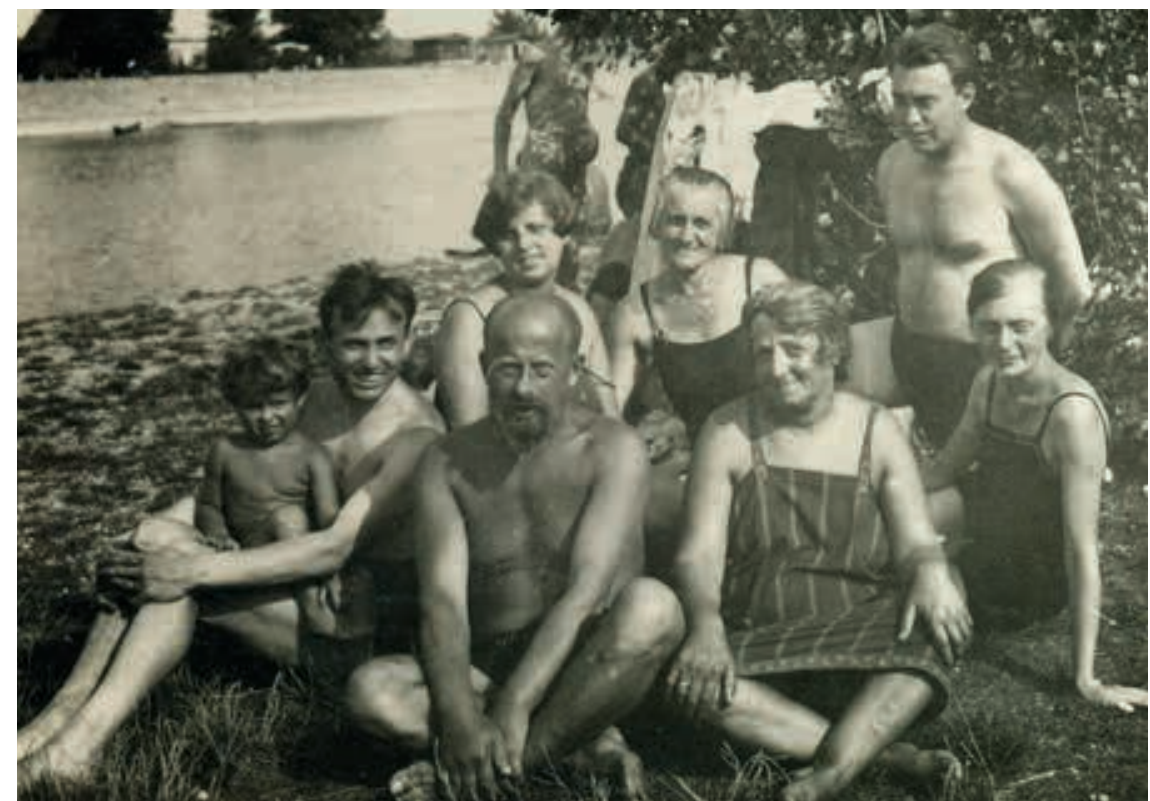

-Zwempartijtje in het in de zomer van 1926. Nelly Klein met haar ouders Klein en de Grooman moederszijde. een tweejarige odyssee. Eerst ging het naar de interneringskampen in de zone in Zuid-Frankrijk die (nog) niet door de Wehrmacht was bezet: St. Cyprien, Gurs, Les Milles. Uiteindelijk werd hij op 17 augustus 1942 vanuit het station Drancy-Le Bourget naar Auschwitz gedeporteerd. Zijn gezin hoorde niets meer van hem sinds zijn deportatie naar Zuid-Frankrijk.

Zoals in alle andere landen die door de Duitsers werden bezet, was de vervolging en uitroeiing van de Joodse bevolking een van de voornaamste doelstellingen van de bezettingsmacht in België. Daartoe werkten vooral het bestuur van de Militärbefehlshaber en de Judenreferat samen. Die laatste viel onder het bevel van het militaire bestuur, de Sicherheitspolizei en de SD. Op 4 augustus 1942 vertrok de eerste trein van Joodse bevolking door razzia's te organiseren. Nelly en haar moeder doken onder als huishoudsters - illegaal, en dus volledig overgeleverd aan de grillen van de werkgever. Ze werden niet zelden uitgebuit. In de herfst van 1942 werkte Nelly bij een zeer oud echtpaar in het westen van Brussel. Toen Nelly de gevel, bekleed met tegels, met een schrobber met een lange steel aan het reinigen was, kwam Judith Fürst voorbij, haar vriendin uit de vroegere jeugdgroep van het Joodse comité, en ze vroeg iets in de zin van: 'Ben je het niet beu om de tegels van de rijken te schrobben? Wil je niet liever samen met ons in de weerstand werken?' Zo herinnert Nelly het zich.

De activiteitbinnen de weerstand waarvoor Judith Fürst mensen ronselde, werd Travail allemand (TA) genoemd De idee om de kennis van de Duitse tal van communisten in ballingschap te gebruiken voor de weerstand ontstond in de zomer van 1941, in eerste instantie in de communistische partij van Frankrijk (KPF). Na 
de Duitse overval op de Sovjetunie en de daarmee verbonden schending van het Ribbentrop-Molotow-Pact werden binnen de partij de mogelijkheden besproken om verzet te bieden tegen de Duitse bezetter. Het TA werd in december 1941, op aansporing van de KPF, door functionarissen van de communistische partij van Oostenrijk, Duitsland en Tsjecho-Slovakije in Parijs in het leven geroepen. De acties van het TA pasten vermoedelijk ten dele in het kader van de KPD-afdeling in ballingschap: 'Ontwrichtingswerk onder de Duitse bezettingstroepen'.

Terwijl Belgische weerstandgroepen via Engeland geld en wapens kregen, gold dat niet voor Oostenrijkse of Duitse groepen. Het TA in België had weliswaar contact met Belgische weerstandsgroepen, maar ze waren niet te vinden voor de gedachte hen wapens te geven, aangezien die bijzonder schaars waren. In hun ogen waren ze nu eenmaal ook Duitsers of Oostenrijkers en dus niet bepaald betrouwbaar. Daarom werden de jonge mensen eerst bijna volledig aan hun lot overgelaten en ze namen vooral hun toevlucht tot weerstandsvormen waarbij hun Duitse moedertaal een voordeel opleverde. Eén vorm van verzet was in elk geval exclusief voor jonge vrouwen voorbehouden: het Mädelarbeit (meisjeswerk) of Soldatenwerk

\section{MÄDELARBEIT OF SOLDATENWERK BIJ HET TA}

Nelly Klein was al snel één van zowat twintig vrouwen met valse papieren. De meesten kwamen uit Oostenrijk, enkelen ook uit Duitsland, Rusland en Polen en meestal hadden ze geassimileerde Joodse ouders. Sommige jonge vrouwen waren al vóór hun emigratie actief in linkse jeugdorganisaties. Ze moesten doelgericht flirten met militairen van de Wehrmacht die in België waren gestationeerd. De vrouwen, die meestal als Jodinnen en communisten een dubbel risico liepen om vervolgd te worden, waren vaak per twee onderweg en spraken op publieke plekken af met de militairen. Op die manier probeerden ze eventuele intimidaties te voorkomen. Het doel van die contacten wordt heel treffend 'ondermijning van de weerbaarheid' genoemd. Tijdens sesprekken moesten ze twiifel zaaien over het nutvan de oorlog en met namer over 'eindoverwinning', in de hoop dat de soldaten zouden deserteren. Boventen moeste onnage uitvoeren. Ze probeerden informatie te verzamelen overgeplande mutatie van eenheden, probeerden te weten te komen hoe de stemming onder de militairen was, waarvoor men bevreesd en waarover men bezorgd was. De militairen van de Wehrmacht moesten voor de verzetszaak gewonnen worden en in de kazernes een kritische houding tegenover de oorlog verspreiden, relevante interne informatie doorspelen, op hun reis naar huis vlugschriften over de grens smokkelen, deserteren en zich aansluiten bij de Karintisch-Sloveense partizanen of later ook bij de geallieerde troepen.

De vrouwen ontmoetten de militairen onder andere op vlooienmarkten, waar ze zich aanboden als tolkbij taalproblemen. De soldaten waren doorgans blij meisjes en jonge vrouwen te ontmoeten waarmee ze Duits konden spreken. Zo eindigde een dergelijke 'toevallige' ontmoeting vaak in een kroeg. Bij de eerste ontmoeting moesten gesprekken over oorlog en politiek worden vermeden, om eerst persoonlijk toenadering te zoeken. Pas bij de volgende ontmoeting moesten de vrouwen bij wijze van militaire verkenning met leden van de Wehrmacht verschillende thema's aansnijden. Het bleek echter dat de meeste jonge militairen zelf niet wisten wat hun meerderen planden. Na de ontbinding van de Komintern in mei 1943 door Stalin, die alle landen tegelijk opriep om hun nationale belangen zonder vreemde invloed te vertegenwoordigen, spraken de jonge vrouwen uitsluitend Oostenrijkse leden van de Wehrma ht aan. De strijd om de nationale autonomie van Oostenrijk werdbinnen de Oostenrijkse groep in het TA een belangrijk propagandapunt, vermoedelijk door de chauvinistische houding van vele Duitse KPD-functionarissen en door de Verklaring van Moskou van 1 november 1943 over de bijdrage van de Oostenrijkers tot de bevrijding van hun land.

Nelly Klein ontmoette slechts zeer weinig militairen meer dan een of twee keren, omdat de contacten maar weinig opleverden. De meeste jonge soldaten geloofden onwrikbaar in de eindoverwinning, zegt ze:

Ik herinner me de onderdanigheid aan de Führer en de verheerlijking van discipline als

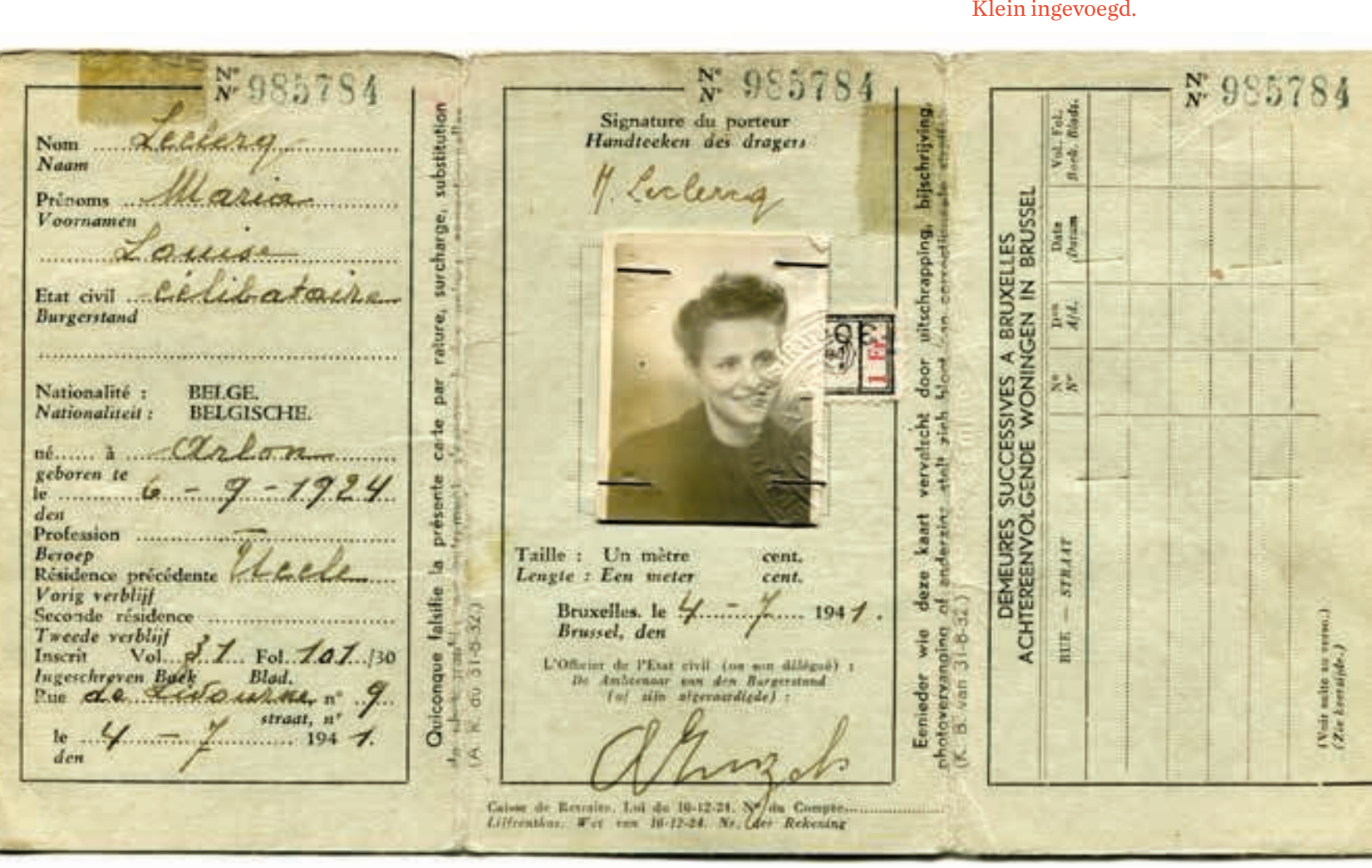


- Nelly Klein kort na de bevrijding samen
met enkele kameraden Bovenste rij vil.n.r.: Wiesinger, waarschijnlijk Helene Meyersohn, onbekend, Nelly Kle
onbekend, Régine Krochmal; Onderste Krochmal; Onderste rij
v.l.n.r.: Cilly Spitz, Hertha Stuberg.

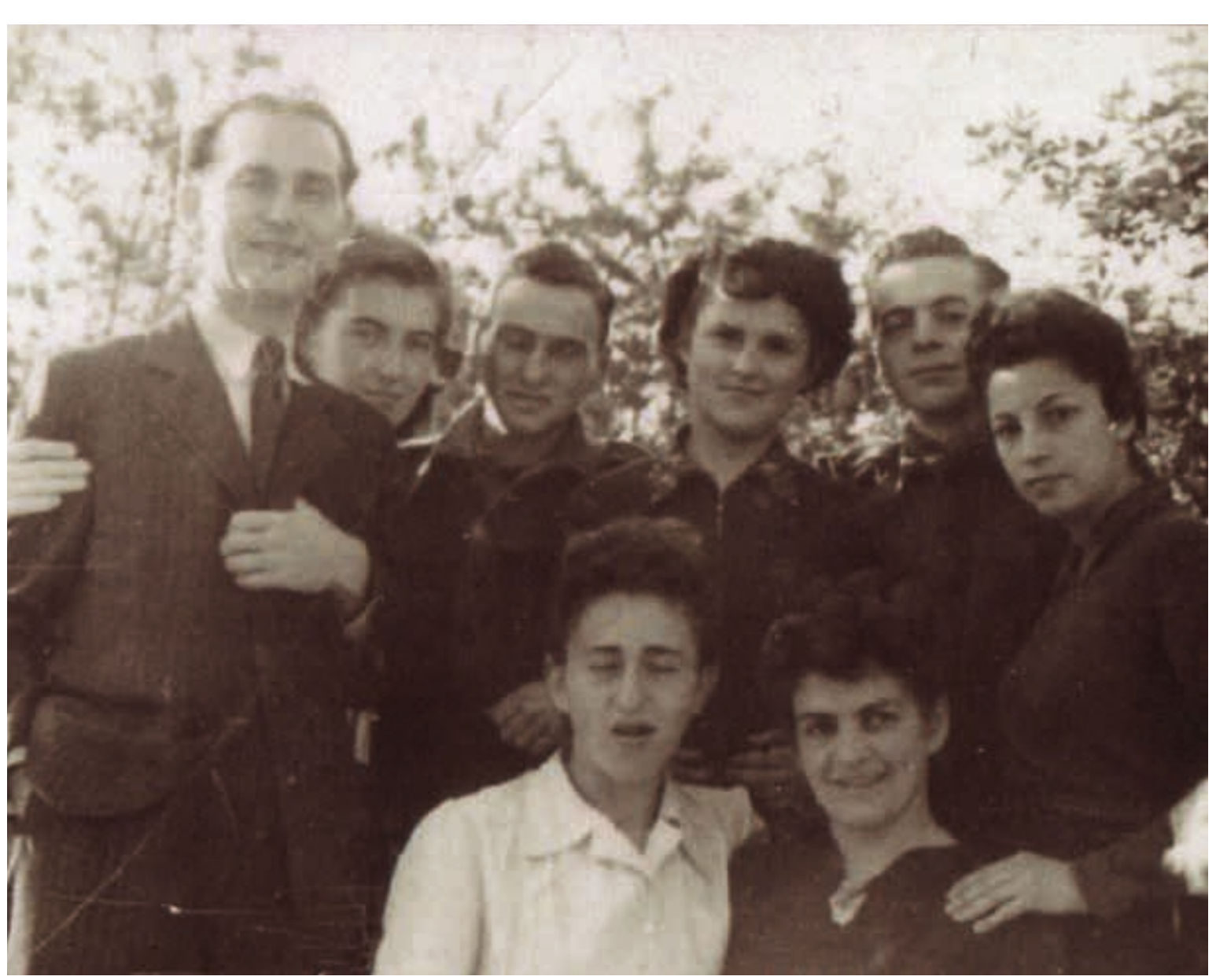

Het was niet eenvoudig om de tegenstanders van de oorlog en het nationaalsoonaalsocialisten, soms met twijfelaars. Er waren er zelfs bij die pochten met foto's van partizanen, soto's zou staan als de Russen zouden komen, gezien de onvoorstelbare gruwelen die ze zelf ginder hadden gepleegd. Zo denkt Nelly Sturm vandaag terug aan haar pogingen om soldaten ertoe te bewegen de bevelen te weigeren:
Afgezien van mijn schrik bij deze ontmoetingen had dit werk voor mij ook steeds een fascinerende kant. Stelt u zich dat eens voor! Wij, de verstoten jonge meisjes, waagden ons tot aan de muil van het beest om te weten te komen wat het in zijn buik had... En dan riepen wij ze op om een revolutie te ontketenen tegen hun meerderen! Ik vergat nooit om hen bij het afscheid met een goedige glimlach te zeggen: 'Jullie kunnen deze oorlog niet winnen. Jullie gaan hem verliezen. Je kunt er dus maar beter meteen mee ophouden.' cialisme te identificeren. De vrouwen hadden soms te maken met overtuigde natizou sta

volkeren hadden [...]. De nazipropaganda had ongehoorde schade in de hoofden en harten van deze mensen veroorzaakt. Deze mannen in uniform, die blij waren dat ze uit hun dorpen en kleine steden en uit de verveling en banaliteit van hun leven van elke dag konden

Er deserteerden effectief enkele militairen van de Wehrmacht met de steun van de jonge Oostenrijkse dames. In de zomer van 1942 slaagden ze er zelfs in om contact op te nemen met militairen uit het strafbataljon 999, die vanuit Antwerpen naar Noord-Afrika moesten inschepen. De soldaten daar waren vaak politieke tegenstanders van het nationaalsocialisme die in gevangenissen of concentratiekampen gedwongen werden gerekruteerd voor militaire operaties met extreem veel verliezen. De verliezen in de rangen van het $\mathrm{TA}$ waren ook heel groot. Tijdens opleidingen van de Wehrmacht werd gewaarschuwd voor 'Duitstalige bolsjewistische vrouwen'. Vele jonge vrouwen betaalden daardoor hun inzet met hun leven. Op ondermijning van de weerbaarheid stond de doodstraf, net als op hoogverraad. Andere vrouwen werden zwaar gefolterd en gedeporteerd naar Auschwitz. Nelly Klein overleefde de nationalsocialistische vervolgingen, matr har ouders werden verno natiollo's van Nely's sturmfuhrer prof. rijksuniversiteit Stratsburg. Hirtorganiseerde de noord op Joodse gevangenen in de gaskamer van het concentratiekamp Natzweiler-Struthof. Hun lijken moesten worden geprepareerd om in het anatomisch instituut een verzameling te vormen voor antropologisch onderzoek volgens de nationaalsocialistische rassenkunde. Studenten van de toekomstige generaties moesten ook na de vernietiging van de Joden de mogelijkheid hebben om de 'kenmerken van hun ras' te bestuderen. Toen August Hirt vroeg om voor dat doel Joden van Auschwitz naar het concentratiekamp Natzweiler-Struthof over te brengen, maakte ook Elisabeth Klein deel uit van de groep.

Nelly Klein maatte de bevrijding in Brussel mee. Na een bewogen en politiek Nelly Klein maakte de leven met etappes in België, Oostenrijk, de DDR, Frankrijk en de Duitse Bondsrepubliek overleed Nelly Sturm op 9 maart 2017 op 92-jarige leeftijd in Berlijn. 